\title{
REESTRUTURAÇÃO SOCIOESPACIAL DO TERRITÓRIO
}

CEARENSE

\section{RESTRUCTURATION SOCIO-SPATIALE DU TERRITOIRE CEARENSE}

\section{THE SOCIAL-SPATIAL RESTRUCTURING CEARÁ'S TERRITORY}

\author{
Sergiano de Lima Araújo \\ Geógrafo e mestre em Geografia pela Universidade Estadual do Ceará (UECE). \\ Prof. do Departamento de Geografia da Universidade Estadual Vale do Acaraú-UVA \\ Av. Jonh Sanford, 1845 - Bairro: Junco Cep: 62030-000 - Sobral - CE - Brasil \\ Email: Sergiano_araujo@hotmail.com
}

\begin{abstract}
Resumo
O presente trabalho tem como objetivo principal estudar a dinâmica do território cearense, recentemente incorporadas à lógica da produção globalizada. Para tanto, faremos uma discussão do processo de reestruturação produtiva no espaço, retratando as inúmeras contradições e ambigüidades advindas com a inserção de alguns lugares dentro desse processo. A referida análise procura entender o movimento do capital a partir do período pós-segunda guerra, em que a terceira revolução tecnológica faz com que o mundo passe por um intenso processo de expansão do capital, no tocante à dispersão na produção de mercadorias, provocando, com isso, sucessivas e surpreendentes metamorfoses no espaço geográfico. O Estado do Ceará é estudado na perspectiva de um espaço que se insere nesse novo período histórico sob os ditames do capital monopolista com o período técnico-científico-informacional. Nesse caso, tentamos fazer uma leitura que busque apreender como se processa a seletividade territorial e a competitividade dos lugares em tempos de globalização.
\end{abstract}

Palavras-chave: Globalização; Ceará; seletividade territorial; modernidade.

\section{Résumé}

Le présent travail a pour principal objectif d'étudier la dynamique du Ceará, a récemment intégré la logique de la production mondialisée. Pour cela, nous allons discuter du processus de restructuration dans l'espace, illustrant les nombreuses contradictions et les ambiguïtés résultant de l'insertion de certains endroits dans ce processus. Cette analyse vise à comprendre les mouvements du capital de la période après la seconde guerre, dans laquelle la troisième révolution technologique fait tourner le monde à travers un intense processus d'expansion du capital, en termes de dispersion dans la production de biens, ce qui, avec cela, métamorphoses successives et étonnant dans l'espace géographique. L'état de Ceara est étudié dans la perspective d'un espace qui se trouve dans la nouvelle période historique sous la dictée du capital monopoliste dans la période technico-scientifique-informationnel. Dans ce cas, essayez de faire une lecture qui cherche à comprendre comment il gère la sélectivité et de la compétitivité territoriale des places en temps de mondialisation.

Mots-clé: mondialisation, sélectivité territoriale, vecteurs de la modernité. 


\begin{abstract}
This work aims to study the dynamics of the state of Ceará, Brazil, recently incorporated to the logic of globalized production. Thus, we discuss the restructuring process of its production, until now with many contradictions and ambiguities. This analysis seeks to understand the movement of capital (market) from of the post-Second World War period, where the third technological revolution made the world passed through an intense market expansion, causing successive and amazing metamorphosis in the geographic area. This state is studied from a new historical period perspective (market or capital monopoly) during the scientific technical information moment. We also investigated how this processes caused a territorial selectivity and competitiveness of this place in times of globalization.
\end{abstract}

Key-words: Globalization; Ceará; territorial selectivity; modernity.

\title{
Globalização e seletividade territorial
}

Após a Segunda Grande Guerra Mundial, presenciamos no mundo um desenvolvimento de um período técnico-científico-informacional ${ }^{1}$, fazendo com que passássemos por um acelerado processo de globalização da produção e do consumo, trazendo no seu bojo reflexos diretos para todos os setores da sociedade contemporânea. O progresso técnico em áreas como a informática e as telecomunicações, associado à diminuição dos custos dos transportes, favorecem a integração dos mercados nacionais e a internacionalização dos processos de produção em muitos setores da economia.

Esse acelerado processo de globalização econômica se intensifica a partir de 1970 quando o capital passa a vivenciar uma grande crise orgânica em sua própria estrutura (MÉSZÁROS, 2002). Vale ressaltar que essa crise, vivenciada pelo capitalismo, já era sentida mesmo com o crescimento econômico do período pós-guerra, mas vai eclodir sobremaneira, com o colapso do sistema Bretton Woods e a crise do petróleo na OPEP.

Nesse período, o capitalismo começa a experimentar, de uma forma mais aguçada, os efeitos de seus próprios antagonismos. Se por um lado, precisou lançar mão de estratagemas de acumulação cada vez mais sofisticados através do avanço dos sistemas técnicos; por outro, começou experimentar os limites econômicos de suas ações.

1 O Período técnico-científico-informacional é um dos mais importantes conceitos desenvolvidos por Milton Santos (1985, 1996, 2001) para explicar o impacto do processo de globalização no território. Para ele o atual período revela a nova composição técnica orgânica do espaço, construído com o conjunto técnico inerente ao novo ciclo da civilização mundial, com conteúdo crescente de ciência, tecnologia e informação. 
Também coadunando com essa tese, Monié \& Silva (2003), esse ciclo do capitalismo quando dizem que a reestruturação produtiva se intensifica no mundo a partir da década de 1970, tendo os sistemas técnicos um papel decisivo na emergência e consolidação de novos arranjos produtivos, tecnológicos, organizacionais, logísticos e financeiro, ocasionando uma intensa competitividade territorial no mundo, tanto dos lugares, como dos grandes conglomerados econômicos.

Com a crise orgânica do capital, o mundo passa a ser palco de grandes movimentos de flexão e inflexões políticas e econômicas, tudo isso com vistas a possibilitar um novo ciclo virtuoso do capitalismo mundial. Torna-se perceptível um sentido de movimento de transformação desse estado de coisas.

O território passa a receber inúmeras inovações tecnológicas (microeletrônica, novos materiais, novas formas de organizar o processo produtivo) e a vivenciar um vertiginoso movimento de mudanças políticas tais como: o fim da URSS, o fim do Welfare State, a formação de blocos econômicos regionais (União Européia, Mercosul, dentre outros) o que dão lugar a um novo ciclo de compressão do espaço-tempo de Harvey (1989).

Com a crise do capital, a necessidade de expandir mercados torna-se cada vez mais urgente. Buscando aquilatar seus mercados e campos de investimentos, o capital busca espraiar tanto territorialmente, quanto em novos segmentos de atuação. Assim, em termos de território, os países ou economias periféricas passam a ser o alvo principal dessa nova etapa ou ciclo de acumulação. O clássico pensador de $O$ Capital nos fala que, “... impelida pela necessidade de mercados sempre novos, a burguesia invade todo o globo. Necessita estabelecer-se em toda parte, para explorar em toda parte, criar vínculos em toda parte” (MARX, 1980, p.12).

Ainda sobre as necessidades de expansão do capital, Mészaros (2000) também nos contempla com uma excelente reflexão quando aborda sobre a nova racionalidade do capital sobre os auspícios da modernidade.

É sob a égide da "bandeira do mercado" que surge a metamorfose no modelo de produção, uma vez que o modelo taylorista-fordista já não dava mais conta das demandas erigidas pela crise. Assim, adaptando-se às necessidades impostas pelo sistema de produção, surge o modelo toyotista ou processo de produção flexível. 
As mudanças que ocorrem dentro do próprio modo de produção vai provocar dentre outras coisas, a globalização do capitalismo, pensada, articulada e comandada pelos países mais ricos do mundo; a explosão tecnológica da terceira revolução; a ascensão do neoliberalismo; a substituição do sistema de gestão da produção e trabalho taylorista fordista pelo toyotismo. Ou seja, a suplantação de um sistema hierarquizado e inflexível (rígido) por um mais flexível, polivalente e com crescente nível de automação dos meios de produção.

Além dessa mudança significativa no sistema de produção, a política neoliberal surge também como uma das respostas para a crise do capital, e passa a redesenhar as relações entre Estado, sociedade e mercado, trazendo implicações diretas para todas as esferas da sociedade. Para melhor historicizar a gênese do Estado neoliberal (ANTUNES, 1999).

Nesse caso, o Estado vai atuar com políticas em diferentes áreas, mas no seu cerne há um modelo global e uníssono, em fases distintas, voltado para a acumulação do capital, orquestrado em maior ou menor grau pelo Estado.

Nessa fase de transição para um novo modelo de acumulação, o Estado intervém no sentido de criar condições de implantar um novo modelo de acumulação. No anterior, o processo de acumulação se dava sob a hegemonia do capital industrial e a intervenção do Estado era no sentido de criar as condições para a reprodução do capital dentro desse modelo de acumulação.

No período seguinte, com a hegemonia do capital financeiro, tendo como principais agentes as corporações transnacionais, o Estado passa a ser o auxiliar desse novo centro do sistema, investindo nos setores e nos lugares com maiores possibilidades de acumulação ampliada do capital. Essa diferenciação no papel do Estado dá-se em função da diferenciação da divisão internacional do trabalho no nível da economia e da sociedade como um todo.

Destarte, essa nova racionalidade se espraia no território, numa busca frenética pela mais-valia, acentuando ainda mais a repartição de objetos e de atividades entre os diversos lugares. Aprofunda ainda, a divisão territorial do trabalho e leva conseqüentemente, a uma maior especialização produtiva dos lugares (SANTOS, 2001).

Dessa maneira, o território passa a cristalizar novas feições políticas, econômicas e culturais como conseqüência da nova divisão territorial do trabalho. Sendo assim os 
novos eventos produzidos pelos agentes hegemônicos da economia mundial, impactaram e transformaram os lugares, produzindo signos que chocam-se como os velhos, em um movimento de conflito e cooperação, gerando, assim, verdadeiros híbridos no espaço (SANTOS, 1999).

Toda a emergência de uma unicidade técnica (SANTOS, 2006) acabou com a distância e o tempo entre os lugares e com isso acelerou os fluxos mundiais (materiais e imateriais) possibilitando, dessa forma, uma maior dissociação geográfica da produção e do consumo globalizados.

David Harvey (1989) diz que, com o advento da globalização, a forma de se vivenciar o espaço e o tempo, passou a sofrer constantes modificações. Essas mudanças nos dão a impressão de que os espaços vão diminuindo e o tempo parece transcorrer de forma cada vez mais acelerada, mas, na verdade, essa sensação de rapidez e fluidez espaço-tempo refere-se ao tempo do capital, ao tempo do fazer,ao tempo da nova racionalidade produtiva pós-fordismo.

A compressão espaço-tempo, ainda de acordo com autor, tem como resultante o frenesi de homens e mulheres que vivem no período técnico-científico-informacional e que passam a vivenciar, como nunca na história, uma sensação de encurtamento das distâncias geográficas e de aumento da velocidade das transformações sociais, políticas e econômicas.

Nesse estudo, David Harvey (1989) faz uma analogia do tempo atual com a física e descreve essa experiência como "encurtamento do espaço-tempo" e a interpreta como uma característica muito própria do capitalismo exacerbada em nossos dias. Nesta experiência, popularizou-se para a opinião pública através dos meios de comunicação, partindo de um pressuposto de que o mundo inteiro é vizinho, e, que o amanhã já está acontecendo. Isso tudo foi possível graças à criação dos mitos, fábulas, que se fundiram em torno da globalização.

Ao mesmo tempo que produz essa aceleração do tempo, a expansão capitalista produz também uma ampliação do espaço, na medida em que a lógica expansionista da acumulação concretiza-se num movimento de penetrar as esferas da vida social que lhe apresentam por diante, sem quaisquer fronteiras, sejam políticas, culturais ou geográficas (ARRIGHI, 1996). Dessa forma países, regiões e lugares que se constituíam 
áreas de reserva do capital passam a ser usadas de forma corporativa conforme os interesses dos atores envolvidos.

Santos (2001), por sua vez, esclarece inúmeras questões quanto às fábulas criadas pela globalização. O autor chama-nos à atenção para que percebamos a existência de dois mitos que ganharam notoriedade e magnetizaram a sociedade como um todo, o mito da aldeia global e o mito do espaço e do tempo contraídos.

A ideologia da globalização, segundo o autor, funciona como uma cortina de fumaça para escamotear a realidade socioespacial, pois quando analisamos essa aldeia dita global, temos que atentar para as inúmeras ambigüidades, conflitos e contradições no uso ideológico desse termo, pois o "mundo presencia uma fácil comunicação entre as pessoas, mas o que na verdade está posto é que essa comunicação se dá com intermediação de objetos técnicos".

\begin{abstract}
A informação sobre o que acontece não vem da interação entre pessoas, mas do que é veiculado pela mídia, uma interpretação interessada, senão interesseira dos fatos". Ainda com relação aos mitos produzidos, criados, inventados e personificados pelo atual período, merecem destaque, para o autor, o mito do espaço e do tempo contraídos que, para ele, são prodígios da velocidade. Como o autor ainda reforça “... Só que a velocidade apenas está ao alcance de um número limitado de pessoas, de tal forma que, segundo as possibilidades de cada um, as distâncias têm significações e efeitos diversos e o uso do mesmo relógio permite economia de tempo (SANTOS, 2001 p.41).
\end{abstract}

Portanto, a globalização é, de certa forma, o ápice da internacionalização do mundo capitalista, sendo caracterizada como um estágio, uma etapa, como um movimento no desenvolvimento capitalista, que só se tornou possível graças à universalização das técnicas (SANTOS, 2001).

Ainda segundo Santos (1996), as diversas mudanças ocorridas na história da humanidade sempre tiveram como fator condicionante o desenvolvimento de um conjunto de técnicas, que permitiram, com isso, novas significações para o desenvolvimento das relações sociais. As técnicas aconteciam de forma sistêmica, de forma que cada processo evolutivo representou uma época da história mundial. Não se trata aqui de pensar que as técnicas se desenvolveram autonomamente, pelo contrário, foi o resultado de um acúmulo historicamente produzido pelas sociedades.

A primeira perspectiva permite uma interligação entre todas as técnicas com o advento da chegada da técnica da informação que, através da cibernética, da informática, da robótica e da eletrônica garantem um acelerado comércio mundial. A segunda, a velocidade dos sistemas de informação que proporcionam ao tempo do fazer, 
do produzir, um novo significado, uma simultaneidade jamais alcançada na história da humanidade, permitindo o que Milton Santos chamou de convergência dos momentos (SANTOS, 2001, p.07). Ou seja, em todos os lugares, a cada dia o local se torna intimamente ligado com o global.

Mas o avanço da unicidade técnica (SANTOS, 1996) não acarretou o desaparecimento das velhas técnicas como muitos pensam. Estas, por sua vez, passaram a ser utilizadas pelos chamados atores não hegemônicos, no caso os países ou as empresas de economias periféricas, diferentemente do que ocorre com as técnicas modernas, que são incorporadas pelos atores hegemônicos do capital internacional, em sua maioria, pelos grandes conglomerados econômicos.

Esses conglomerados econômicos, que possuem o domínio hegemônico das técnicas modernas e da maioria das transações comerciais e financeiras, são comandados pela atual tríade dominante do capitalismo pós-fordismo, no caso, Estados Unidos, Japão e União Européia. A grande maioria dos fluxos de comércio, de capitais, de investimentos e de trocas comerciais estão, indubitavelmente, sob o domínio desses atores hegemônicos do comércio mundial.

Toda essa distribuição espacial desse conjunto de técnicas, facilitada pela informação, fez com que houvesse uma fragmentação do processo produtivo no âmbito internacional, trazendo consigo uma reorganização das economias do mundo, tornandoas cada vez mais interdependentes. Dessa forma, os avanços dos sistemas técnicos colocam a possibilidade do modo de produção capitalista acontecer em todos os lugares.

Para Hirst \& Thomposon (1998, p.13), a economia mundial internacionalizou-se em suas dinâmicas básicas, passando a ser comandada, dominada e articulada pelas forças dos mercados incontroláveis que têm, em seus principais atores econômicos e agentes de troca, verdadeiras corporações transnacionais que não devem lealdade a Estado-nação algum e se estabelecem em qualquer parte do mundo em que a vantagem de mercado impere.

O Brasil, a partir da década de 1970, da crise do capital, passa a ser uma das regiões seletivas do capitalismo mundial como tentativa de suplantar a crise. O capital ávido por novos territórios, novos mercados, seleciona áreas do território brasileiro para participar efetivamente da produção e do consumo globalizado, o que vai promover a aceleração em todos os setores da vida social. Essa aceleração, especialmente dos fluxos 
(SANTOS, 1996), passa a dirimir inúmeras mudanças econômicas, sociais, culturais, políticas e espaciais, mudando mesmo a percepção das pessoas e das empresas em relação ao espaço geográfico local e mundial.

A racionalidade técnico-científica torna-se predominante devido à possibilidade de interferência em todos os lugares. O capital, dessa forma, vai produzir no território brasileiro inúmeras metamorfoses, sendo suas marcas contundentes: o intenso processo de crescimento das trocas comerciais, a seletividade territorial, as novas relações de produção, o crescente processo de urbanização.

Isso se torna possível graças aos surpreendentes avanços nos sistemas técnicos do período pós-guerra e que se intensificam a partir da década de 1970 com uma nova revolução nos meios de comunicação e circulação Santos (1996), viabilizou mudanças significativas na produção e em toda dinâmica territorial, fazendo com que os agentes hegemônicos da economia e da política tivessem uma maior disponibilidade do território, ampliando, assim, sua escala de atuação.

O território brasileiro passa a vivenciar uma aceleração na sua dinâmica socioespacial intensificando-se a modernização da produção agrícola e industrial, a expansão do comércio e dos serviços. Sendo, dessa forma, as inovações técnicoscientíficos-informacionais as articuladoras das novas relações sociais de produção e que conseqüentemente passam a comandar mudanças abruptas no espaço geográfico.

Cabe aqui lembrar que, diferentemente da à tríade dominante (Estados Unidos, Europa e Japão) do capitalismo mundial, a evolução dos sistemas técnicos no Brasil não se espraiou de forma igualitária em todo território, pelo contrário, selecionou determinadas regiões, segmentos econômicos e determinados grupos sociais. A região concentrada (SANTOS, 1996) foi a porção do território que mais se beneficiou com o progresso técnico, promovendo, dessa forma, mudanças na composição técnica do território (sistemas de engenharia) e na composição orgânica (biotecnologia, inovações químicas, cibernética, informática, etc).

Vale ressaltar que os signos da modernizção que se instalam em algumas áreas do território nacional, articulam de forma surpreendente o Estado e capital numa simbiose que essas duas forças se tornam uníssonas nos proposições e ações para que o país ingresse na nova ordem do capitalismo mundial. As mudanças ocorridas em vários circuitos produtivos se baseiam fundamentalmente na seletividade territorial e na 
especialização produtiva e como conseqüências, promovem significativas mudanças na estrutura, na forma, na aparência, na fisiologia e na fisionomia do território nacional.

A função do Estado como havíamos retratado anteriormente, vai exercer uma importância singular para a efetivação e consolidação do novo modelo de desenvolvimento em curso. Se no período anterior o processo de acumulação se dava sob a hegemonia do capital industrial, em que a intervenção do Estado era no sentido de criar as condições para a reprodução do capital dentro desse modelo de acumulação. No período seguinte, com a hegemonia do capital financeiro, tendo como testas-de-ferro as corporações transnacionais, o Estado passa a ser o auxiliar desse novo centro do sistema, investindo nos setores com maiores possibilidades de acumulação ampliada do capital. Essa diferenciação no papel do Estado se dá em função da diferenciação da divisão internacional do trabalho ao nível da economia como um todo (BRANDÃO FILHO, 2005).

Nessa nova fase do capitalismo mundial, o Estado brasileiro vai atuar em duas frentes em relação ao fortalecimento da estrutura produtiva. Uma ação intervencionista, predominante nos períodos anteriores aos anos 80, e uma ação de caráter regulatório e mediador, mais precisamente na fase atual. Essas diferenças tornam-se evidentes nas conjunturas políticas do Estado durante a chamada ditadura militar e posterior transição democrática, acentuando a entrada do neoliberalismo no Brasil. Evidenciando um papel classista do Estado em defesa da acumulação capitalista, por outro lado revela que a sociedade civil perde espaços políticos organizados para lutar por seus direitos de cidadania (POSSAS, 1996).

Deve-se ter em conta que mesmo antes dos anos 70-80, o Estado intervém de forma incisiva no sentido de planejar, arquitetar o território nos países em desenvolvimento, para as novas investidas do capitalismo. O desenvolvimento da produção aparece estreitamente relacionado aos conhecimentos organizativos e técnicos, com infra-estrutura e com base cultural, se edifica sobre ciclos que veiculam a oferta com a procura. As regiões não se desenvolvem no vazio, senão dentro de um entorno complexo em que são registradas relações tanto de tipo econômico como de poder. A criação de infra-estrutura é a condição prévia para qualquer tipo de desenvolvimento. 
A intervenção do Estado na base econômica do país mudou de qualidade na década de 70, passando a atuar no sentido de articular a base agrária como a industrial, em sintonia com o mercado externo, fazendo com que a economia brasileira se inserisse no cenário com um padrão contemporâneo".

\section{Modernização do território: a construção de um discurso}

O território brasileiro vem sofrendo, desde meados do século XX, um constante processo de reestruturação e globalização. Isso se deve ao fato de a revolução tecnológica, impingindo no território, seus principais signos, de forma muito acelerada nas inúmeras atividades econômicas. Essa transformação exigiu a incorporação de novos sistemas de objetos e sistemas de ações (SANTOS, 1999), visto que os anteriores se mostravam incompatíveis com as novas formas de produção, distribuição e consumo, provocando uma reestruturação dos sistemas técnicos.

Esses casos podem ser vislumbrados nas regiões Sul, Sudeste e parte do CentroOeste, pois pelo fato de terem sido áreas prioritárias tanto para o Estado quanto para o capital, presenciaram um intenso desenvolvimento econômico, diferentemente do que ocorreu com o Nordeste brasileiro, que ainda hoje convive com as consequiências desse atraso científico-tecnológico.

Além desse atraso tecnológico em relação a outras regiões do território nacional, um fator também deve ser considerado quando tentamos analisar o grande mosaico social que é a Região Nordeste.

O Nordeste brasileiro sempre foi marcado por discursos e práticas políticas conservadoras, arcaicas e tradicionais das elites locais, que, para permanecerem e perpetuarem-se no poder e, principalmente, manterem intocadas suas estruturas agrárias, disseminaram para o restante do país um discurso de que o Nordeste é uma "região problema" (ARAÚJO, 1992, p.02). Esse discurso difunde a idéia de que é uma região da seca, da miséria, da incapacidade de gerar emprego e renda para a sua população, portanto uma região incapaz de receber políticas de desenvolvimento no setor produtivo, pois as condições climáticas não ofereceriam condições para grandes investidas do capital. 
Imbuídos nesse discurso ideológico predominante, as oligarquias regionais obtiveram grandes financiamentos do Estado através das agências de desenvolvimento regional (DNOCS, SUDENE, BNB) para a chamada política hidráulica (ARAÚJO, 1992, p.02) que tinha como meta primordial a construção de açudes, barragens, poços artesianos em grandes propriedades particulares que ajudavam no fortalecimento do setor de fazendeiros-pecuaristas que, em tempos de estiagens, conseguiam evitar as perdas de seus rebanhos, uma de suas maiores riquezas.

Fundamentados não só na ideologia, mas também em práticas políticas arcaicas, as oligarquias construíram um discurso marcante com ressonância em toda sociedade brasileira, atribuindo a inviabilidade econômica da região aos azares climáticos e a pouca densidade pluviométrica.

Para estes, a inexpressiva base econômica regional estava intimamente ligada aos fatores relacionados aos longos períodos de estiagem. Mostrando estampada na mídia nacional a miséria absoluta da maioria da população, a elite agrária e industrial nordestina conseguia sensibilizar e emocionar os mecanismos econômicos e políticos do país, atraindo, dessa forma, vultosas quantias para implementarem seus projetos (construção de açudes, barragens, poços artesianos em suas propriedades particulares, empréstimos a fundo perdido para compra de terras e gado, dentre outros). No entanto, sobrava para o restante da população as famosas políticas compensatórias de cunho assistencialista (frentes de emergência, cestas básicas, etc) que serviam apenas para minimizar a fome e favorecer o êxodo rural em massa na região.

No início da década de 1980, o Nordeste brasileiro insere-se na nova ordem estabelecida pelo grande capital. Surge então, um novo discurso, modernizador, composto pela burguesia industrial e por setores da administração pública, que tentam promover uma ruptura com o conservadorismo clássico que imperava na região. ${ }^{2}$

A partir desse período, o discurso do atraso e da miséria, advindos dos azares climáticos, passam a ser substituídos pelas elites agrárias-industriais, pelo discurso da modernidade, da globalização, do liberalismo econômico e do desenvolvimento sustentável. A ideologia do novo e do moderno passa a ser difundida por alguns setores

2Para aprofundar essa discussão, recomenda-se consultar o excelente trabalho de Josênio Parente \& José Maria Arruda (Org.). A era Jereissati-Modernidade e mito, Fortaleza: Edições Demócrito Rocha, 2002. 
da administração pública, das oligarquias indústrias e do grande capital, que ora dominavam as esferas do poder.

Para esses interventores, a ciência e a tecnologia tornaram-se capazes de suplantar todos os problemas de ordem ambiental. Portanto, a revolução técnicocientífica (SANTOS, 1996) na agropecuária modificaria todos os circuitos produtivos, na medida em que toda produção econômica no campo “...deixa de ser uma exclusividade (uma) esperança ao sabor das forças da natureza para se converter numa certeza sob o comando do capital" (SILVA,1996 p. 16).

A elite burguesa agrária-industrial parte da prerrogativa de que o clima não é mais uma força contrária ao desenvolvimento da região. Ao contrário, o sol se tornou um dos principais aliados para a inserção da região no processo de globalização econômica, sendo o turismo, o agronegócio e por último a política de atração de empresas (interiorização da indústria). Os três principais vetores de desenvolvimento no processo de modernização da economia cearense.

\section{Ceará: a instauração de uma "nova era de mudanças"}

No final da década de 1980 e início dos anos 1990, com a ascensão ao poder de um grupo de empresários ligados ao Centro Industrial do Ceará (CIC $)^{3}$, órgão ligado a Federação da Indústria do Estado Ceará (Fiec), autodenominado de "governo das mudanças", o Ceará passa por um momento de intensa ebulição política, econômica e ideológica. Pautados na ideologia do novo e do moderno, esses empresários constroem um conjunto de imagens que tenta distinguir o território cearense dos demais estados da região Nordeste sob o prisma da reestruturação produtiva. O discurso, expresso por essas novas lideranças, tenta substituir a ideologia dos coronéis e afirmam possuir uma nova forma de fazer política, que segundo eles, distingue-se completamente das práticas políticas arcaicas de seus antecessores em se tratando do trato com a coisa pública (SILVA, 2000).

3Fundado em 1919, o Centro Industrial do Ceará - CIC é uma entidade política, formada por industriais, empresários e profissionais liberais e tem como objetivo principal ser um agente indutor do processo de desenvolvimento do Estado (FIEC, 2006). Disponível: http://www.fiec.org.br Em: 01/05/2006. 
Esses empresários tidos como modernos passam a adotar duas posições com relação ao desenvolvimento econômico: em nível nacional, passam a defender o liberalismo econômico, a livre concorrência dos mercados, o enxugamento da máquina estatal, a venda de empresas públicas e a extinção de outras, como forma de estimular a eficiência, a competência e a moralização da máquina pública. Em se tratando de política doméstica, abandonam essa conceituação para propor a intervenção planejada do Estado com a construção de grandes obras para a atração de investimentos.

O período passa a ser marcado por uma política de grandes investimentos tanto por parte do Estado quanto do grande capital para que, através dos aqui denominados vetores de modernidade (turismo, indústria e agronegócio), possam inserir algumas áreas seletivas do território cearense dentro da lógica da produção globalizada.

\section{Os vetores de modernização da economia cearense}

$\mathrm{Na}$ área do turismo, com a missão de fortalecer o Estado como destino turístico nacional e internacional, no ano de 1995, cria-se uma Secretaria de Turismo do Estado (Setur). A secretaria serve para atrair o capital internacional do setor hoteleiro e das grandes companhias de turismo mundial, divulgando as belezas naturais, mostrando as condições climáticas favoráveis para a vinda dos grandes conglomerados turísticos, com isenção fiscal, modernização das rodovias e capacitação de mão-de-obra.

Para a consolidação dessa política de inserção no Ceará no eixo do turismo globalizado, o órgão tem consolidado parcerias com setores públicos e privados, captando negócios e investimentos para o desenvolvimento da infra-estrutura e o crescimento socioeconômico. Além disso, desenvolve ações de marketing em parceria com o trade turístico e operadoras nos mercados nacional e internacional (SETUR, 2006).

O governo estadual intervém no território através de financiamentos provenientes do Programa de Desenvolvimento do Turismo no Nordeste (Prodetur/NE) através de sistemas de objetos e sistema de ações (SANTOS, 1996), que vão dar suporte a essa política de modernização do setor. Dentre as ações mais importantes estão as obras ligadas aos transportes e ordenamento urbano de alguns municípios que se inserem nessa nova dinâmica da atividade turística. 
Dentre as obras mais importantes podemos citar algumas que tiveram grande repercussão na reconfiguração territorial: Na cidade de Fortaleza tivemos a reforma e ampliação no Aeroporto Internacional Pinto Martinse suas vias de acesso, construção do Centro Dragão do Mar de Arte e Cultura, ampliação do Centro de Convenções e requalificação da orla de Fortaleza. Ainda faz parte desse grande projeto de modernidade, a construção do Trem Metropolitano de Fortaleza (Metrofor) que com orçamento da ordem de US\$ 502 milhões, encontra-se em pleno processo de execução.

Através de recursos do Prodetur I, foram recuperados e construídos $255 \mathrm{~km}$ de estradas, merecendo destaque as rodovias

Costa sol nascente (litoral leste) e Costa do sol poente (litoral oeste), que cortam praticamente as principais praias do litoral cearense, procurando sempre interligar grandes avenidas duplicadas e bem sinalizadas com a malha viária de Fortaleza. Além disso, grande parte dos recursos do Prodetur está sendo direcionada para obras de urbanização e requalificação de áreas turísticas de vários municípios ${ }^{4}$ do litoral e das serras úmidas do Estado.

Com todos esses investimentos, tem-se atraído cadeias da rede hoteleira mundial (principalmente de portugueses e espanhóis) que segundo o Instituto de Comércio Exterior Português (ICEP), é um dos principais destinos do capital lusitano no Brasil. O Estado aparece no segundo lugar do ranking dos preferidos pelos portugueses, só perdendo para São Paulo. De acordo com o ICEP, existem 122 empresas portuguesas no Ceará, o que representa 20,7\% do número total dos empreendimentos lusitanos no País (SETUR, 2006). A construção de hotéis e resorts em algumas praias distantes do litoral cearense vem abrindo com isso, caminhos para as companhias aéreas e marítimas colocarem Fortaleza na rota do turismo mundial, tornando-se comum a conexão da cidade com várias outras metrópoles do mundo através de vôos charter, que desembarcam no Aeroporto Internacional Pinto Martins, assim como os cruzeiros marítimos que chegam ao Ceará pelo porto do Mucuripe.

Com as inúmeras políticas públicas implementadas pelo Estado para a atividade turística, tivemos um constante crescimento do fluxo turístico no Ceará e conseqüentemente uma elevada participação do setor no Produto Interno Bruto do Estado (PIB). No ano de 1995, o fluxo de turistas para Fortaleza chegava 486 mil

4 Dentre os municípios do Estado que estão beneficiados com obras do Prodetur/NE, podemos citar: Fortaleza, Aquiraz, Aracati, Acaraú, Barroquinha, Beberibe, Caucaia, Camocim, Chaval, Camocim, Cascavel, Cruz, Itarema, Granja, Jijoca de Jericoacoara, Itapipoca, Jijoca de Jericoacara, Paraipaba, Paracuru, São Gonçalo do Amarante, Trairi e Viçosa do Ceará. 
turistas anuais, em 2004 passou para 1,8 milhão e 2004, O impacto no PIB estadual saltou de 4,0\% para $11,7 \%$ no mesmo período (SETUR, 2006) $)^{5}$.

Mas mesmo diante de números tão promissores com relação ao turismo no Estado, verificamos que o modelo de turismo adotado no Ceará tem favorecido consideravelmente a especulação imobiliária de imensas reservas naturais, no crescimento substantivo da exploração sexual infanto-juvenil, na concentração de terras e de renda na medida em que a construção das redes de hotéis no litoral tem provocado a expulsão de inúmeras comunidades tradicionais como: pescadores, marisqueiras e catadores de caranguejos, como também vem provocando incalculáveis impactos socioambientais.

No caso da indústria, como sendo um dos vetores de modernidade, o Estado atua sob duas frentes estratégicas para a atração de novas empresas principalmente ligadas aos setores têxtil ${ }^{6}$ e calçadista. Primeiro o Estado intervém no sentido de criar uma agressiva guerra fiscal com os outros estados da federação, reduzindo de $25 \%$ a $75 \%$ do Imposto de Circulação de Mercadorias e Serviço (ICMS) ${ }^{7}$, o que tem despertado o interesse de inúmeras empresas nacionais do eixo Sul e Sudeste do país. Vale ressaltar que o percentual e o tempo de isenção de impostos são determinados pela localização geográfica do investimento, ou seja, quanto mais distante de Fortaleza, ampliam-se o percentual e a elasticidade do período de isenção que pode chegar até quinze anos.

Paralelos aos incentivos fiscais oferecidos pelo o Estado, as prefeituras concedem descontos na redução dos tributos municipais ${ }^{8}$ (principalmente a alíquota para o Imposto Sobre Serviço/ISS), desapropriam e doam terrenos e instalam novos distritos industriais para atrair novos investimentos e garantir novos empreendimentos

5Disponível: http://www.setur.ce.gov.br:7778/setur/Estatisticas. Em:26/04/2006

6De acordo com a Associação Brasileira da Indústria Têxtil da Confecção, em 2004, o Ceará possuía um total de 131 indústrias têxteis e 1.888 de confecção. Destaque esse, que colocava o Estado como segundo maior parque têxtil do país ficando atrás apenas de São Paulo.

7 De acordo com dados do Instituto de Pesquisa e Estratégia Econômica do Ceará (IPECE), ao longo da década de 1990 o Programa de Incentivos Fiscais do Ceará (FDI) aplicou recursos líquidos da ordem de 1,3 bilhão de reais pelo Tesouro Estadual.

8Os municípios oferecem uma redução de até 5\% na alíquota sob o Imposto Sobre Serviço (ISS) para as empresas que se instalarem em seu território. 
no município. Em parceria com o Estado, tratam também de dar condições de infraestrutura para viabilizar as unidades industriais ${ }^{9}$.

E se tratando do setor calçadista, que tem sido um dos principais beneficiários com a política fiscal adotada na ultima década, o resultado desse processo foi a instalação de mais de 400 micro e pequenos produtores ligados a produção (calçados plásticos, calçados femininos e masculinos de couro, os calçados femininos e masculinos sintéticos e os calçados esportivos - tênis), que por sua vez passaram a se articular dentro do circuito espacial da produção calçadista por intermédio de dez grandes empresas âncoras ${ }^{10}$.

A territorialização dessas empresas está fortemente associada ao custo de mãode-obra barata que varia entre $13 \%$ a $21 \%$ sobre o custo total, sendo que o preço da mão-de-obra no Ceará, é, de aproximadamente $40 \%$ inferior ao preço pago nas regiões Sul/Sudeste, onde se encontram os três maiores pólos produtores: Franca, em São Paulo; Novo Hamburgo, no Rio Grande do Sul; e Nova Serrana, em Minas Gerais. Com isso, a redução do custo total no setor, devido à mão-de-obra barata chega ser entre $5,2 \%$ e $8,4 \%$.

A grande oferta de força de trabalho incide diretamente nos lucros das empresas e paralelamente na pauperização dos trabalhadores assalariados, pois mesmo desempenhando as mesmas funções dos assalariados do eixo Sul/Sudeste, os proletários da indústria local recebem salários que chegam a ser três vezes menores do que os dessas regiões do país ${ }^{11}$. Os baixos salários pagos pelas empresas que instalam-se no Ceará se dão principalmente pelo fato de que nas regiões Sul e Sudeste tinham que lidar com trabalhadores mais organizados e com sindicatos fortes que pressionavam por salários e condições de trabalho melhores. No Ceará, elas encontram categorias desorganizadas, o que dá para trabalhar com salários menores. Algumas dessas empresas nem chegam a contratar com carteira assinada, mas por meio de cooperativas que terceirizam os serviços.

9Jornal O Povo - Caderno de Economia, 07 de maio/2006.

10Nos últimos dez anos, com o processo denominado de "guerra fiscal", dez das maiores empresas brasileiras de calçados, se territorializaram principalmente no interior Ceará. São elas, a Grendene (Nordeste, Sobral e Crato), Paquetá Nordeste, Aniger do Nordeste, Dakota Nordeste, Vulcabrás Nordeste, HB Batarello, Democrata, Musa Calçados e Dilly.

11Jornal o Estado/Cadernos Setoriais, 11 de novembro/ 2004. 
O emprego gerado no setor industrial cearense tem um custo bastante elevado. De acordo com Pesquisa e Estratégia Econômica do Ceará (Ipece), ao longo da década de 1990 o Programa de Incentivos Fiscais do Ceará (FDI) do Governo Estadual, aplicou recursos líquidos da ordem de $\mathrm{R} \$ 1,3$ bilhão, gerando com isso somente 70.000 empregos diretos.

O próprio Banco Mundial ${ }^{12}$, em um estudo feito no ano de 2001, revela que somente no ano de 2000, o Estado investiu R \$ 292 milhões em incentivos fiscais, uma quantia razoável quando se leva em consideração que esse dinheiro saiu de um estado com renda per capita de US\$ 1.700. Os incentivos trouxeram empresas caras e modernas, cujo principal traço, como se sabe, é a falta de apetite para gerar postos de trabalho. No ano de 2000 o Estado gastou nada menos que $48 \%$ de seu aporte financeiro destinado a investimentos com esse tipo de incentivo. Porém, gerou uma modestíssima quantia de 19.150 empregos, o equivalente a $0,8 \%$ da população ativa, a um preço de $\mathrm{R} \$ 16$ mil por cada nova vaga criada.

O relatório do Banco Mundial é bastante incisivo com o modelo de desenvolvimento implementado no Ceará nas últimas décadas quando afirma que este não vem corrigindo as distorções sociais. A economia cearense cresceu acima da média nacional, mas lembra que o progresso social é uma decepção. O estudo fala de uma pobreza gigantesca, atingindo $58 \%$ de uma população que, depois de se beneficiar de uma pequena melhora no início da década passada, hoje vegeta na falta de perspectiva. Numa descoberta chocante, o trabalho revela que a vida de quem se encontra na faixa dos $20 \%$ mais pobres tem piorado de modo regular e contínuo.

Portanto, como pudemos perceber, a política fiscal implementada com recursos provenientes do Tesouro Estadual não vem surtindo os efeitos esperados, empregam um contingente muito pequeno dos trabalhadores ativos, recrutam pessoal pouco qualificado e com isso pagam baixos salários. O necessário seria que no ato da assinatura dos protocolos de instalação, tivessem cláusulas que contemplassem garantias tanto para a arrecadação dos cofres públicos como para os trabalhadores. Os contratos deveriam exigir que após o fim do incentivo fiscal as empresas 
permanecessem no território cearense, por um período no mínimo duas vezes ao tempo recebido de incentivos e ainda que elas fossem responsáveis em criar programas permanentes de qualificação e capacitação de mão-de-obra.

Já a agropecuária cearense durante muitos anos baseou-se na pecuária extensiva (bovinos, caprinos e ovinos), na agricultura de subsistência (feijão, milho, mandioca) e no extrativismo vegetal (castanha de caju, cera de carnaúba etc.). O Ceará, por não apresentar um grande desenvolvimento em técnicas agrícolas para a região semi-árida, encontrou de certa forma limitações com relação ao manuseio das práticas agrícolas modernas.

Com a reestruturação produtiva inicia-se um processo da racionalização do espaço agrário voltado para o agronegócio, como isso o desenvolvimento de uma agropecuária moderna, científica passa a ser um dos três vetores escolhidos para impulsionar o desenvolvimento econômico do Estado.

Desta forma, Estado e capital privado adotam uma agenda de investimentos pesados, como a construção de fixos (estradas, pontes, eletrificação rural, construção de açudes e canais) para inserir algumas áreas do território cearense na lógica do agronegócio. Os vales úmidos (vales do Jaguaribe e do Acaraú) passam a ser a vitrina do desenvolvimento da fruticultura irrigada, como também as áreas serranas ( Baturité e Meruoca) para o cultivo de flores para exportação. Mais recentemente, no final dos anos noventa, a carcinicultura (criação de camarão em cativeiro) nas áreas de mangues e na extensão da planície aluvial do baixo curso do rio Jaguaribe e rio Araraú, passa a ser a mais nova estratégia de uma artificialização do espaço agrário cearense, onde ciência, tecnologia e informação compõe a estrutura central da lógica produtiva.

A região do Baixo Jaguaribe nos últimos anos vem se destacando do restante do território cearense, por um intenso processo de inovações técnicas notadamente associadas à atividade agropecuária provocando dessa forma mudanças significativas na fisionomia do espaço agrário regional (ELIAS, 2002).

O baixo Jaguaribe dentro da lógica da produção globalizada desponta como uma região extremamente promissora nessa investida do capital, desse modo o Ceará inserirse o Ceará no processo de globalização da produção e do consumo. Atualmente, tanto o Estado quanto o grande capital investem maciçamente através de políticas públicas que 
visam criar condições favoráveis para que o capital possa encontrar bases de sustentação e reprodução nessa importante região.

Para subsidiar todo o projeto de modernidade no setor agroexportador, no caso do baixo Jaguaribe vem sendo posto em prática a construção de inúmeras materialidades (SANTOS, 1996) como: a construção de pequenas e médias barragens, e o maior reservatório de água do Nordeste, o Castanhão, que armazenará 6,7 bilhões de metros cúbicos de água, sendo o referido açude o coração de um grande sistema de interligação de bacias hidrográficas, a construção de perímetros públicos de irrigação no caso do Tabuleiros de Russas que irrigará uma área em torno de 22.000 hectares nos municípios de Morada Nova, Limoeiro do Norte e Russas, além da expansão de outros perímetros como o Jaguaribe-Apodi.

A fruticultura irrigada nos últimos anos vem ganhando bastante destaque, sendo considerada o novo símbolo da modernização agrícola. A estratégia posta em prática pelas grandes empresas é articular o mercado local com o global através da produção de frutas, definindo dessa forma, novos padrões de produtividade e competitividade dos lugares produtores.

Com as inúmeras políticas públicas implementadas nos últimos anos para dinamizar o setor agroexportador, várias empresas ligadas ao ramo da fruticultura se instalaram na região do baixo Jaguaribe. Só da segunda metade dos anos 1990 para cá, um número considerável de médias e grandes empresas ligadas ao setor do agronegócio se territorializaram na região, graças à ação efetiva do Estado na construção de um ambiente institucional e de infra-estrutura para a realização lucrativa de seus negócios no Ceará.

A instalação da multinacional Del Monte Fresh Produce ${ }^{13}$, no município de Quixeré, é um bom exemplo do interesse de grandes empresas nacionais e internacionais no baixo Jaguaribe. Esta empresa é, na verdade, parte de um grande conglomerado multinacional do ramo alimentício cuja sede está localizada nos Estados

13 "A marca Del Monte nasceu no final do século XIX, anos de 1880, em Oakland no estado norteamericano da Califórnia. No decorrer de boa parte do século XX, a Del Monte diversificou e verticalizou sua atuação, indo desde a produção de frutas e legumes frescos até à industrialização desses produtos e sua distribuição nos mercados mundiais. Hoje a Del Monte Fresh Produce tem seu principal centro administrativo nas Ilhas Cayman, na sua capital George. Com atuação nos cinco continentes, a empresa é considerada hoje a terceira no setor de produção, comercialização e beneficiamento de frutas in natura do mundo" (ALBANO, 2005). 
Unidos. Esta multinacional é considerada uma das principais companhias de alimentos dos Estados Unidos e do mundo.

Outra atividade econômica que vem despontando dentro desta lógica do agronegócio e que se encontra em franca expansão na região do baixo Jaguaribe é a carcinicultura (criação de camarão em cativeiro). Essa atividade vem se constituindo como importante arranjo territorial produtivo da agropecuária cearense na medida, que vem incrementando a balança comercial $^{14}$ do Estado, mas por outro lado vem produzindo incalculáveis impactos negativos em termos sociais, territoriais e ambientais.

Essa especialização produtiva territorial em curso, é, marcada pelo surgimento de inúmeras estratégias especialmente políticas, econômicas e ideológicas com vistas a promover uma nova divisão territorial do trabalho. Basta citar que no caso da carcinicultura e da fruticultura na região no Baixo Jaguaribe onde um pequeno número de grandes empresas através de dezenas de pequenos e médios empresários do setor, articulados com as mais diversas ações estatais comandam praticamente toda a produção e comercialização e o financiamento das frutas e camarão produzido do Estado, e com isso, conectam a região do Baixo Jaguaribe através do permanente volume de fluxos de mercadorias, informações com os centros de poder em nível mundial, trazendo com sigo novas determinantes para o espaço regional.

\section{Considerações finais}

O território cearense vem sendo incorporado aos ditames da produção moderna através da mudança de sua base técnica e com isso promovendo uma verdadeira reconfiguração territorial. Presenciamos a modernização no espaço, em que se tem uma passagem de um território preso a dinâmicas regionais para um território transnacionalizado, aonde a aceleração dos fluxos, de capitais, informações, mercadorias, que articulados através da unicidade técnica, vem produzindo $\mathrm{e}$ reconfigurando novos lugares, com novos conteúdos, novas formas, com novas funções.

14 Para se ter a dimensão da repercussão desse setor para a balança do Estado, no ano de 2003 de acordo com o Instituto de Pesquisa e Estratégia Econômica do Ceará (IPECE), no ano de 2003 a participação da carcinicultura chegou a ser $10,64 \%$ de tudo que o Estado exportou, chegando ao volume total de exportação de mais US\$ 80 milhões. 
Essa nova fase do capitalismo no território cearense baseado no imperativo da velocidade e da exportação tem promovido mudanças significativas. A necessidade que os agentes privilegiados impingem aos lugares, através do discurso da necessidade de modernização e integração com o mundo "globalizado", sob o risco de se tornarem lentos e esquecidos. Contudo, esse discurso apreende o território apenas como a possibilidade de recurso e não como lugar de vida dos homens lentos, que conformam a maioria da população.

Presenciamos o território sendo usado de forma corporativo para a realização do capital, observamos que esta apropriação está sendo justificado pelo discurso onipotente da economia, que prega como solução salvadora, para diminuir as desigualdades sociais, o aumento das exportações, com o objetivo de manter o equilíbrio da balança comercial.

As grandes empresas ligadas a indústria de transformação, ao agronegócio e ao turismo, utilizam-se dos sistemas técnicos e estratégias modernas de produção para organizarem um território particular para realização dessas atividades econômicas. Criase na verdade, uma região funcional ao seu comando. $\mathrm{O}$ uso seletivo dos sistemas de engenharia tende a aumentar devido à diminuição do número de produtores e empresas que atuam nos respectivos circuitos espaciais produtivos.

As principais empresas criam sistemas de engenharia e escolhem localizações de modo a contar com sistemas de movimentos (estradas, portos, aeroportos), quase privativos, obtendo ao mesmo tempo incentivos fiscais e lucrando com a possibilidade de fluidez na escala global. Essa forma de organização do território, realizada pelas políticas das grandes empresas e financiada, em grande parte, pelo poder público, gera um custo para o Estado e um benefício monopolizado, caracterizando como uma produção e uma circulação desnecessária.

Fica evidente que o processo em curso, baseado no fortalecimento de grandes empresas, vem aprofundando a divisão territorial do trabalho e levando, conseqüentemente, a uma maior especialização produtiva de algumas manchas do território cearense, impingindo nas mesmas um intenso processo de territorialização do capital monopolista. É um território compreendido como valor de uso, sendo apropriado e incorporado pelas empresas e instituições.

Dessa forma, concluímos que o atual modelo de reestruturação produtiva do Ceará, baseado nos denominados vetores de modernização (turismo, indústria e 
agronegócio) não vem promovendo o tão propalado desenvolvimento socioambiental, na verdade o que vislumbramos nessas últimas duas décadas foi o crescimento proeminente da pobreza e da exclusão social nessas porções do território que recebem esses novos eventos.

\section{Referências}

ANTUNES, Ricardo. Adeus ao trabalho? Ensaio Sobre as Metamorfoses e a Centralidade do Mundo.São Paulo: Cortez, 1995.

ARAÚJO, Tânia Bacelar. Nordeste, Nordestes. In: Teoria e debate, 19, $3^{\circ}$ trimestre de 1992, p.2-6.

ARAÚJO, Tânia Bacelar.Nordeste, Nordeste: que Nordestes. In: Desigualdade $e$ desenvolvimento. São Paulo: FUNDAF/UNESP, 1995.

BERNARDES, Julia Adão. A estratégia do capital no complexo da soja. In: CASTRO, Iná Elias de; GOMES;Paulo César da Costa,CORRÊA, Roberto Lobato(Org.). Brasil: Questões atuais da reorganização do território. Rio de Janeiro: Bertrand Brasil, 2002. p. 325-366.

BECKER, Bertha Koff. e EGLER, Cláudio A, G. Brasil: Uma nova Potência Regional na Economia Mundo. Rio de Janeiro: Bertrand Brasil, 1998.

BENKO, Georges. Economia, espaço e globalização. São Paulo: HUCITEC, 1996.

BURSZTYN, Marcel. O Poder dos donos. planejamento e clientelismo no nordeste. Petrópolis: Vozes, 1984.

BRANDÃO FILHO, José Bertoldo. O papel do Estado nas recentes transformações na agricultura moderna do cerrado. In: ENCONTRO DE GEÓGRAFOS DA AMÉRICA LATINA, X; 2005, São Paulo. Anais... São Paulo: AGB, 2005. 1 CD-ROM.

CHESNAIS, François. A mundialização do capital. São Paulo: Xamâ, 1996. 
CORRÊA, Roberto Lobato. Trajetórias geográficas. Rio de Janeiro: Editora Bertrand Brasil, 2001.

EGLER, Cláudio A. G. (Org). Redescobrindo o Brasil: 500 anos depois. RJ Bertrand Brasil, 2000, p. 277-289.

ELIAS, Denise. Reestruturação produtiva da agricultura cearense: rumo á desintegração competitiva e a fragmentação do espaço agrário.In: BORZACCIELLO José; CAVALCANTE Tércia; DANTAS Eustógio (Org.). Ceará: um novo olhar geográfico. Fortaleza: Edições Demócrito Rocha, 2005, p. 429-461.

ELIAS Denise. Globalização e agricultura. São Paulo: Edusp, 2003.

ELIAS, Denise. Integração competitiva do semi-árido. In: ELIAS, Denise e SAMPAIO, Jose Levy Furtado. Modernização excludente. Fortaleza: Edições Demócrito Rocha, 2002. p. 9-36 (coleção Paradigmas da Agricultura Cearense).

ELIAS, Denise. A Atividade Agropecuária do Estado do Ceará no Contexto da Globalização. In: AMORA, Zenilde Baima (Org.). Ceará: Enfoques geográficos. Fortaleza: Funece, 1999. p. 43-72.

ELLUL, Jacques. A técnica e o desafio do século. Rio de Janeiro: Ed. Paz e Terra, 1968. FREDERICO, Samuel. Sistemas de movimento no território brasileiro: os novos circuitos espaciais da Soja. Campinas, São Paulo, 2004. 172 p. Dissertação de Mestrado em Geografia - Unicamp.

FREDERICO, Samuel. Sistemas de armazenamento nos novos circuitos espaciais produtivos da soja. In: VI Congresso Brasileiro de Geógrafos. Julho 2004. Goiânia-GO. Anais. Eixo 05

HARVEY, David. A condição pós-moderna. 12a edição. São Paulo: Loyola, 2003. 
HARVEY. A Produção capitalista do espaço. São Paulo: Annablume, 2005.

HOBSBAWM, Erik J. Mundos do trabalho: novos estudos sobre a historia operária. São Paulo: Paz e Terra, 2000.

HOBSBAWM, Erik J. A era dos extremos: o breve século XX 1914 -1991. São Paulo: Companhia das Letras, 1995.

IANNI, Octavio. A Sociedade global. Rio de Janeiro: Civilização Brasileira, 1995.

JUNIOR, Anchieta Dantas. Turismo é a bola da vez no Ceará. Diário do Nordeste, Negócios, Fortaleza, p. 06, 20 jan. 2006.

KOSIK, Karel. Dialética do concreto. São Paulo: Paz e Terra, 2002.

MARANHÃO, Silvio. A Questão Nordeste. Rio de Janeiro: paz e terra, 1984.

MARX, Karl. O capital - teorias da mais-valia. Livro IV, Vol. 1. Rio de Janeiro: Civilização Brasileira,1980.

MARX, Karl. O capital - crítica da economia política. Livro 1. Rio de Janeiro: Bertrand Brasil,1991.

MAURO, Sílvio. Aquiraz terá maior complexo turístico da AL. O Povo, Economia, Fortaleza, p. 25, 24 nov. 2004.

MÉSZAROS, István. Para além do capital. São Paulo: Claret, 2002.

MONIÊ, Fréderic; Silva Geraldo (Org). A mobilização produtiva dos territórios. Rio de Janeiro: Editora DP\&A, 2003.

OLIVEIRA, Francisco de. Elergia para uma re(li)gião. Rio de Janeiro: Paz e Terra, 1981b. 
PAUL Hirst \& GRAHAME Thompson. Globalização em questão. Rio de Janeiro: Vozes, 1998.

PARENTE \& ARRUDA. A era Jereissati - Modernidade e mito. Fortaleza: Edições Demócrito Rocha, 2002.

PEREIRA \& KAHIL. O uso corporativo do território por empresas e a dinâmica dos lugares: A Embraer em Gavião Peixoto - SP. Caminhos da Geografia IV. Uberlândia, v. 15, junho de 2005. Disponível em:<http://www. ig.ufu.br/revista/caminhos.htm> . Acesso em 18 agosto de 2005.

RAFFESTIN. Claude. Por uma geografia do poder. São Paulo: Ed. Ática, 1993.

SANTOS, Milton. Da totalidade ao lugar. São Paulo: Edusp, 2005.

SANTOS, Milton. O dinheiro e o território. In: Território, Territórios. Programa de Pós-Graduação em Geografia da UFF. Rio de Janeiro, 2002.

SANTOS, Milton. Por uma outra globalização: Do Pensamento Único a Consciência Universal. Rio de Janeiro: Record, 2001.

SANTOS, Milton. A natureza do espaço: técnica e tempo, razão e emoção. São Paulo: Hucitec, 1999(a).

SANTOS, Milton. O território e o saber local: algumas categorias de análise. Cadernos IPPUR, ano II, n.o 2, UFRJ, Rio de Janeiro, 1999 (b). p.15-26.

SANTOS, Milton. O retorno do território. In: SANTOS, Milton; SOUZA, Maria Adélia A. de; SILVEIRA, Maria Laura.(Org.). Território: Globalização e Fragmentação. São Paulo: Hucitec, 1998. p. 15-20. 
SANTOS, Milton. Técnica, espaço, tempo; globalização e meio técnico-científico informacional. São Paulo. Hucitec, 1996.

SANTOS, Milton. Circuitos espaciais da produção um comentário. In: SOUZA, Maria Adélia; SANTOS, Milton (Orgs.). A construção do espaço. São Paulo: Nobel, 1986.

SANTOS, Milton. Espaço e método. São Paulo: Nobel, 1985.

SANTOS, Milton., et.al., O papel ativo da geografia. Um manifesto, LABOPLANFFLCH/USP, XII Encontro Nacional de Geógrafos, Florianópolis, jul. 2000.

SANTOS \& SILVEIRA. O Brasil: território e sociedade no inicio do século XXI, Ed. Record, Rio de Janeiro, 2001.

SILVA, José Borzacchiello da Silva. Pelo retorno da região: desenvolvimento e movimentos sociais no nordeste contemporâneo. CASTRO; MIRANDA; EGLER. Redescobrindo o Brasil: 500 anos depois. $2^{\text {a }}$ Ed. Rio de Janeiro: Bertrand, 2000.

SOUZA \& RAMALHO. Território usado e macrossistema elétrico nacional: o equívoco de um enfoque setorial. In: VI Congresso Brasileiro de Geógrafos, Goiânia, 2004. Eixo 5. pág 1-6.

TOURAINE, A. Crítica da modernidade. Petrópolis - Rio de Janeiro: Editora Vozes, 1999.

ORTEGA \& GASSET, José. Mediação da Técnica. Rio de Janeiro: Ibero-americano, 1973.

POSSAS, Mário. Competitividade: fatores sistêmicos e política industriais: implicações para o Brasil. In: Estratégias empresarias na indústria brasileira: discutindo mudanças. Rio de Janeiro. Editora Forense Universitária, 1996. 
Recebido para publicação em novembro de 2009

Aprovado para publicação em fevereiro de 2010 